\title{
Photovoltaics moving into the terawatt age
}

\section{Eicke Weber}

Eicke R. Weber, "Photovoltaics moving into the terawatt age," Proc. SPIE 10368, Next Generation Technologies for Solar Energy Conversion VIII, 1036803 (25 August 2017); doi: 10.1117/12.2277978

SPIE Event: SPIE Optical Engineering + Applications, 2017, San Diego, California, SPIE. United States 


\title{
Photovoltaics Moving into the Terawatt Age
}

\author{
Eicke R. Weber \\ Berkeley Education Alliance for Research in Singapore BEARS and \\ University of California, College of Engineering, Berkeley
}

\begin{abstract}
Photovoltaic (PV) technology has experienced an amazing development during the last decade, driven by the rapidly decreasing cost at even more rapidly increasing production volumes. This development is discussed from both perspectives, the global PV market and the technology developments accompanying this process. An outlook is given for the possible size of the global PV installations in 2030 and 2050.
\end{abstract}

KEYWORDS: Photovoltaics, Solar Cells, Gigawatt, Terawatt, energy transformation, renewable energy

The transformation of our economy into a long-time sustainable economy is arguably the greatest global challenge for this century. For many areas of the economy, such as the use of limited resources, the transformation will be a slow process, driven by increasing costs of non-sustainable solutions. However, for the transformation of the energy system, a second factor adds special urgency to the rapid transformation of the energy system into a sustainable system: man-made emissions of climate-altering gases such as $\mathrm{CO}_{2}$ and $\mathrm{NO}_{\mathrm{x}}$ are threatening to result in irreversible changes of the planet's climate system, which will lead to global warming and rising sea levels, the beginning of which we are currently experiencing. However, even more dangerous is the prospect that the changing climate will result in increased instabilities of weather patterns, bringing draughts, floods, and storms of hitherto unknown strength. Just in the last years we read reports of hurricans with wind speed approaching $300 \mathrm{~km} / \mathrm{h}$, a strength that leaves little standing upright in the path of such a storm.

As the energy sector is the main cause of man-made emissions of climate-influencing gases, the transformation of our energy system therefore is a prime task that has to be dealt with as quickly as possible. This transformation will be based on two pillars: increasing efficiency in energy use, and increasing fractions of renewable energy in the energy mix. The issue of increasing energy efficiency in buildings, production and transportation is a complex topic, serious studies suggest that this may result in savings of about 50\% compared to business-as-usual scenarios. However, even with increasing efficiency in the use of energy, global energy consumption is expected to increase further, due to the increase of standard of living in the developing countries.

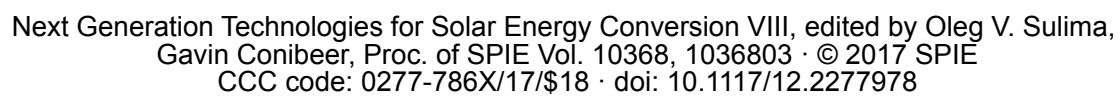


This increasing energy need will have to be supplied by an ever-increasing share of renewable energy, accompanied by an increasing share of electricity in the global energy use. Among all the possibilities to harvest renewable energy, two will be the pillars of the future energy system: harvesting solar and wind energy. All other ways of providing renewable energy, such as utilization of biomass, geothermal energy, wave and tidal energy, will be useful to use where they can be earned, but their potential pales in comparison to wind and especially solar energy: harvesting about 1/10.000 of the sun's energy reaching the earth is sufficient to satisfy all human energy demands, in just one hour the sun provides the energy we need in a whole year!

In a detailed study Hans-Martin Henning and coworkers at Fraunhofer ISE ${ }^{1}$ investigated the German needs of electricity, heat, gas, and other fossil fuels. The goal was to investigate how these needs could be satisfied using an ever increasing fraction of renewable energy, supplying stable and reliable power around the clock for private and commercial use and transportation. The study was based on real, historic data in hourly resolution of energy consumption and supply. It modelled how to satisfy the countries' needs till 2050, based on this hourly resolution. It required many assumptions, e.g. on increasing energy efficiency and increasing fractions of electricity in the energy grid. Thousands of runs were carried out in order to find out the most cost-effective way to satisfy a stable energy supply with increasing fractions of renewable energy.

One important result was that providing $80 \%$ of renewable electricity will be a cost-effective sweet spot, resulting in an energy system that can be maintained at the cost of today's energy system, after the investments into renewable energy supply are made. Going for $100 \%$ requires considerable additional investments especially in the utilization of power-togas. The peak electric power demand of Germany is about 80 Gigawatt (GW), but in order to provide $80 \%$ from renewable energy, it turned out that a total of about $150 \mathrm{GW}$ of PV and $150 \mathrm{GW}$ of off- and onshore wind will have to be installed, i.e. in total about four times the peak power demand. Today, in Germany about $40 \mathrm{GW}$ of PV and wind power are installed, respectively, so these numbers will have to be each quadrupled in order to reach the country's climate goals by 2050 , hopefully even earlier!

Photovoltaic (PV) technology has experienced an amazing development during the last decade. The combination of a capless feed-in price for renewable electricity in Germany with a huge investment credit guarantee program in China resulted in unprecedented growth of the PV industry 2008 till 2013, cf. Figs. 1 - 3, bringing about a price reduction by a factor five in this short time span, from $\$ 3 / \mathrm{Watt}$ to $\$ 0.60 / \mathrm{W}$, and $\$ 0.30 / \mathrm{W}$ today. Today, in most places of the world the cost of PV electricity - about $8 \$ \mathrm{ct} / \mathrm{kWh}$ in Germany, $2.4 \$ \mathrm{ct} / \mathrm{kWh}$ at a recent auction in Dubai - is clearly below the cost of conventional electricity, produced by fossil or nuclear power plants. Looking forward towards 2030, 2050, PV electricity cost below $1 \mathrm{ct} / \mathrm{kWh}$ appears to be realistic, probably much earlier than we imagine today! 


\section{Long-term utility-scale PV system price scenarios}

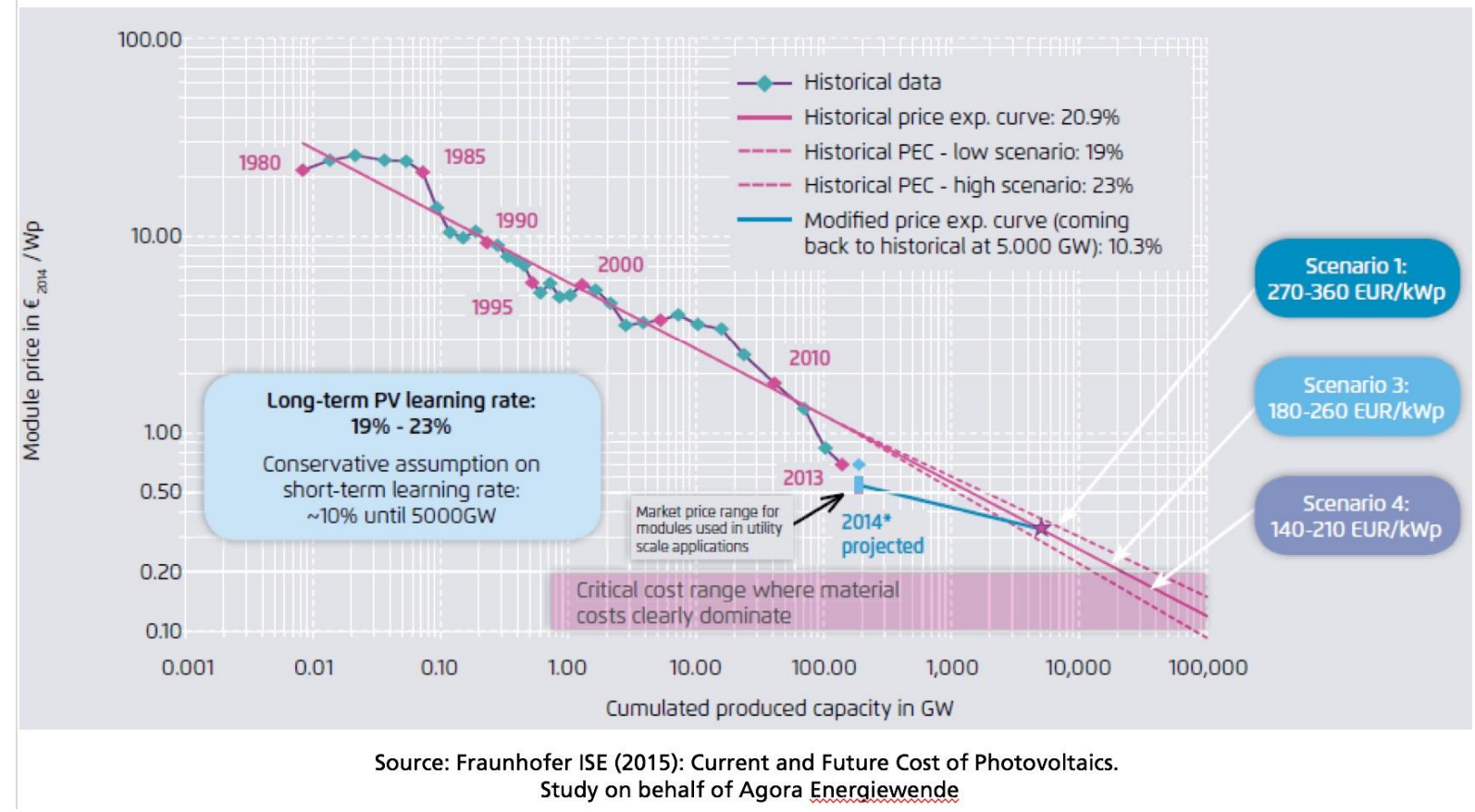

Fig. 1: Price experience curve - the so-called learning curve - of the cost of crystalline Si PV modules since 1980. Please note that the horizontal axis is not time, prices did not come down by waiting, but produced - and deployed - PV capacity: only by reaching the 100s of GW scale could the cost of PV electricity become competitive and today even lower than the cost of electricity from fossil and nuclear sources!

Back in 2010, Sarasin Bank dared to make a prediction of the expected PV world market till 2020, see Fig. 2. At that time, the predicted market growth seemed to be outrageous, the prediction was that the $15 \mathrm{GW}$ world market would grow annually by $20-40 \%$, to reach a market size of $110 \mathrm{GW} / \mathrm{a}$ by 2020 . 


\section{World Market Outlook: Experts are Optimistic Example Sarasin Bank, November 2010}

\section{- market forecast (2010): $30 \mathrm{GW}_{\mathrm{p}}$ in 2014, $110 \mathrm{GW}_{\mathrm{p}}$ in 2020 annual growth rate: in the range of $20 \%$ and $30 \%$}

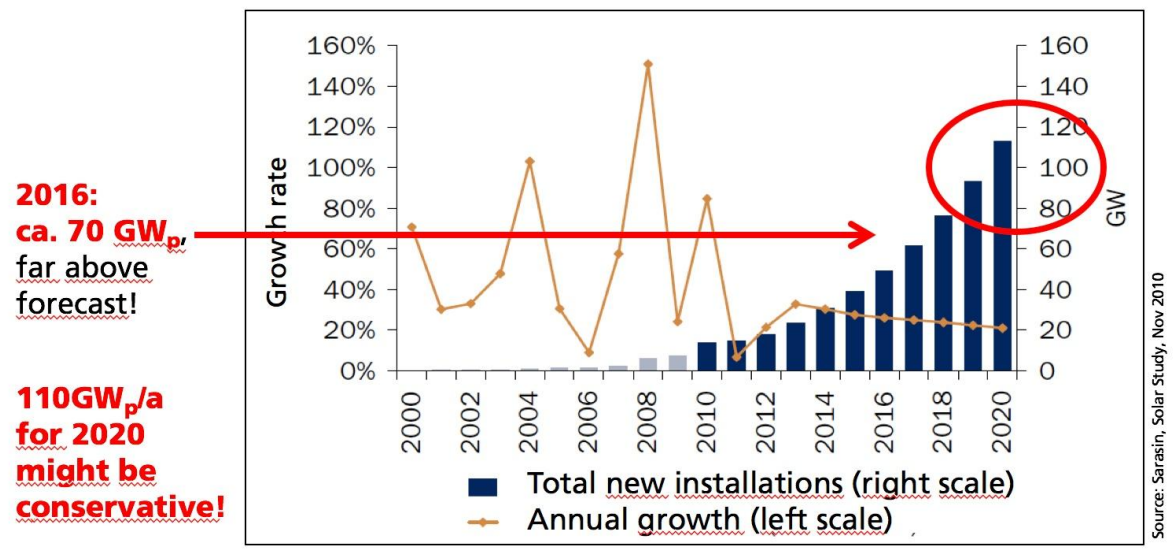

Fig. 2: Expected growth of the PV world market, from a 2010 Solar Study by Sarasin bank.

However, each year since then the real size of the world PV market greatly exceeded the Sarasin predictions, for 2016 the prediction was about $50 \mathrm{GW}$, but the real market exceeded $70 \mathrm{GW}$ of newly produced PV capacity. ${ }^{2}$ Therefore, it is quite safe to predict that the 2020 market will reach or exceed the $110 \mathrm{GW} / \mathrm{a}$ predicted by Sarasin back in 2010, Fig. 2. In other words: from 2015 with a $56 \mathrm{GW} / \mathrm{a}$ market we expect till 2020 a further doubling of the world market, in only five years!

The last five years have been very tough for all PV producers worldwide, and this is best understood by considering the actual PV production and PV sales numbers since 2010, see Fig. 3. The rapid growth of PV production since 2008, driven mainly by new capacity in the different, competing regions in China, was much faster than the growth of the PV world market. In 2012, the market had doubled from 2010, to $30 \mathrm{GW} / \mathrm{a}$, but the production capacity had reached $60 \mathrm{GW} / \mathrm{a}$, double this amount. In consequence, prices tumbled, as is easily visible in the price experience curve, Fig. 1, and by 2013 prices were far below the long-time price experience curve. Many PV producers were forced to sell even below production costs, as cash-strapped producers conducted fire sales of their stock of ready-produced PV modules.

This situation should turn to the better in the coming years, as we will expect another doubling of the PV market that is not yet matched by present production capacity. Therefore, it might be worth to mark 2016/2017 as the start of the 2nd cycle of PV, PV starting to head into the Terawatt scale for PV. 


\section{Global PV Production Capacity and Installations}

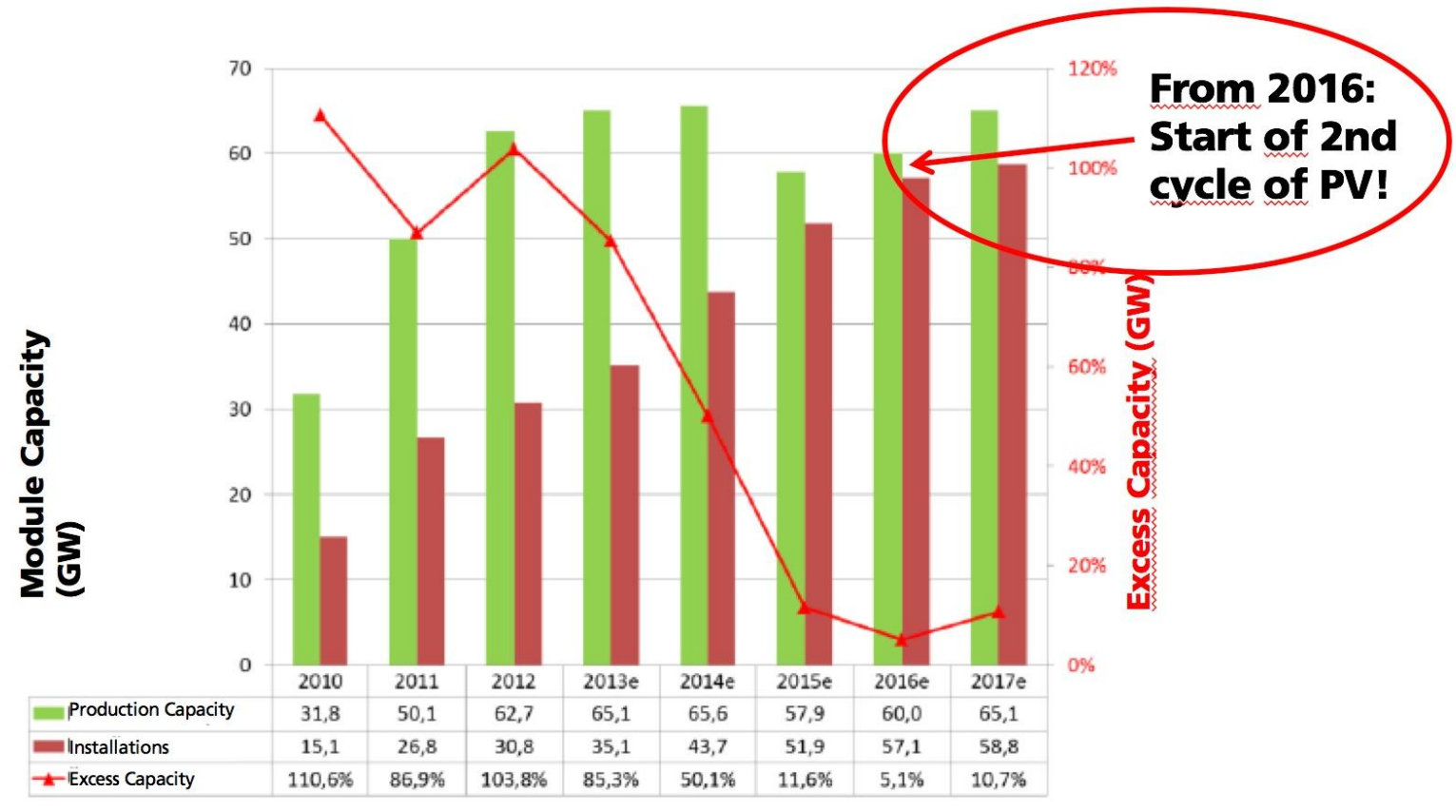

Source: Lux Research Inc. 2012, Grafik: PSE AG, own

Fig. 3: Global annual PV production capacity, actual PV sales, and excess capacity, the difference between both

This was the topic of a workshop in March 2016 in Freiburg, convened by the Global Alliance of Solar Research Institutes GA-SERIS between NREL (USA) Fraunhofer ISE (Germany) and AIST (Japan). The international participants in this workshop agreed that we are at the brink of the second large cycle of PV, we will experience PV deployment to enter the Terawatt scale till 2030, when an expected 3-10 Terawatt (TW) of PV capacity might be installed, see Fig. $4^{3}$. 


\section{Projections to TW-scale PV from TW workshop March 2016}

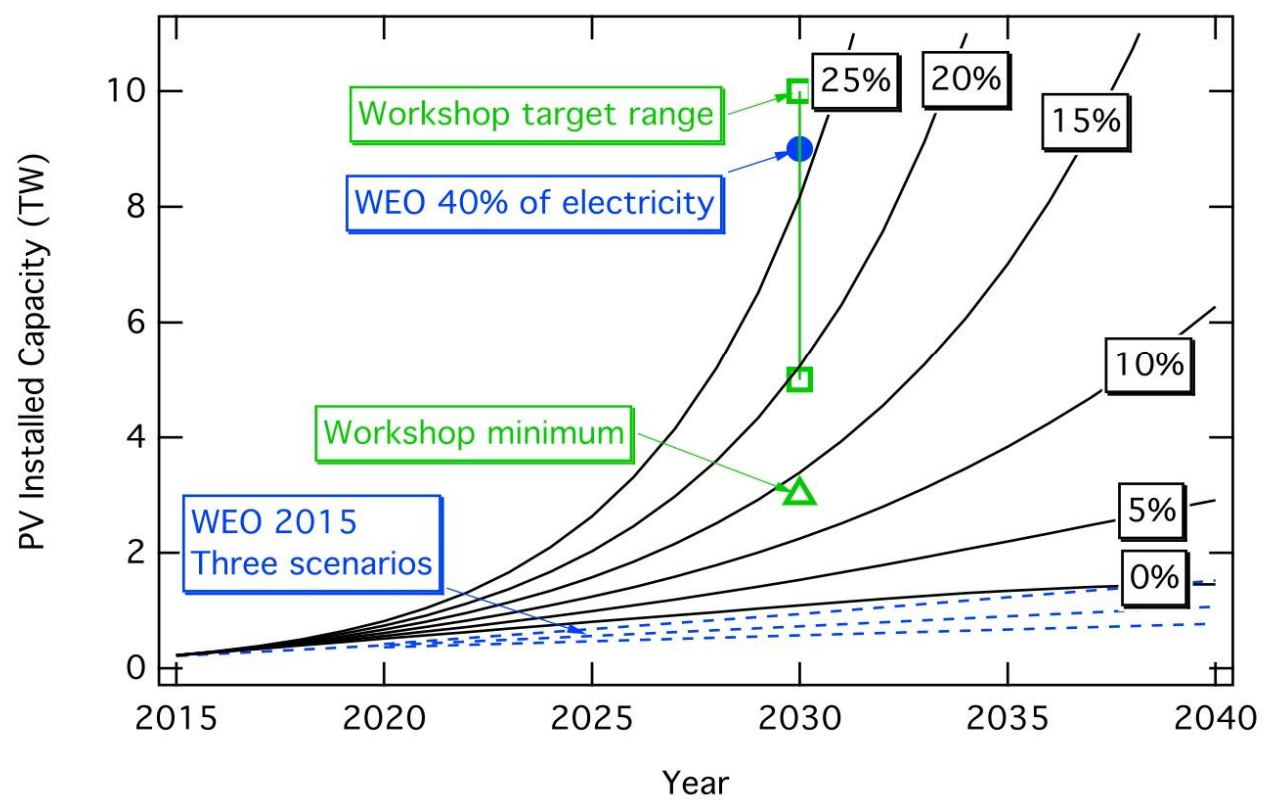

Fig. 4: Projections of the growth of total globally installed PV capacity, developed at the Freiburg workshop ${ }^{3}$

Using simple assumptions, it was projected that just maintaining the 2015 PV deployment rate would result in reaching 1 TW deployment well before $20130 .^{3}$ An annual growth rate of the PV market of $25 \%$ would result in reaching $5-10 \mathrm{TW}$ by 2030 , which still would supply less than $10 \%$ of the world's energy needs. In order to supply by PV just $1 / 3$ of the world's energy needs of about $50 \mathrm{TW}$ expected for 2050, about $70 \mathrm{TW}$ of PV will need to be installed - at good locations, with $2000 \mathrm{hrs}$ of sunshine annually. So, there will be plenty of opportunities for further market growth of PV, the global PV market is still in an embryonic state, comparable to the automotive industry around 1900. Fig. 5 shows that even for the modest assumption of 4-5 TW of installed PV capacity 2050 the graph of the expected global PV installations is very impressive, considering the modest value of about $300 \mathrm{GW}$ installed presently! A similar argument could be made for global wind installations, but this is not our topic here. In addition, we cannot elaborate here whether at this point a worldwide supergrid with East-West electricity transport allowing to follow the sun, large-scale storage, or large-scale power-to-gas technologies might be used to guarantee secure energy supply around the clock. A combination of these approaches presently seems to be the most likely scenario, as could be shown for the example of a high-tech country like Germany. ${ }^{1}$ However, it is worth to note that there is no show-stopper in sight. 


\title{
PV Heading into the Terawatt Range - this is a Disruption!
}

\author{
- Rapid introduction of PV globally is fueled by availability of cost- \\ competitive, distributed energy
}

- In 2050 or before between 4.000 and $30.000 \mathrm{GW}_{\mathrm{p}}$ PV will be installed!

- By 2016, less than $300 \mathrm{GW}_{\mathrm{p}}$ have been installed!

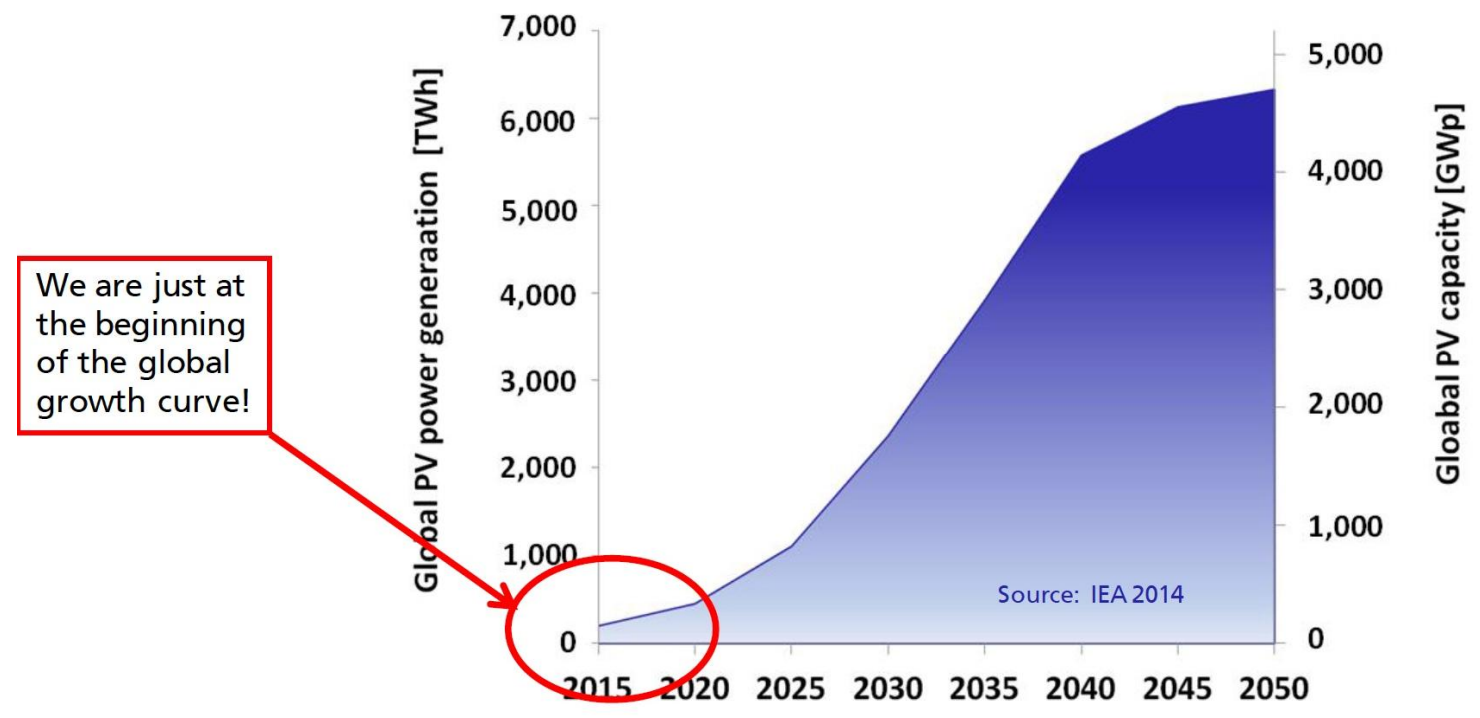

Fig. 5: Projected growth of globally installed PV in one of several different scenarios discussed by the International Energy Agency IEA in 2014.

A key factor for this growth will be continuous technology advances, aimed at higher efficiencies at reduced cost. In addition, solar cell efficiency will be even more important than lowest cost, to optimize energy harvest from a given area. Crystalline Silicon technology currently represents more than $95 \%$ of the global PV market, see Fig. $6 .^{2}$ The remaining about $5 \%$ of the world market is provided by thin-film technologies that 30 years ago provided a full $30 \%$ of the world PV market, as shown on Fig. 6. However, the rapidly decreasing costs of crystalline Si PV, accompanied by rapidly increasing cell efficiencies of this Gigawatt-scale technology, made survival for thin film technologies difficult. They generally offer lower efficiencies at no longer lower cost. Today, only one company is still relevant in this market segment, First Solar, that developed a stable business model offering to build solar parks with CdTe-based thin film modules produced in Gigawatt-scale in their own factories. Other thin-film approaches such as CuIn(Ga)S(Se) (CIGS), organic PV, dyesensitized solar cells or Perovskite-based cells up to now were unable to reach such a large-scale, cost-effective production volume. $^{4}$ 


\section{Global Market Share of PV Technologies Percentage of Global Annual Production}

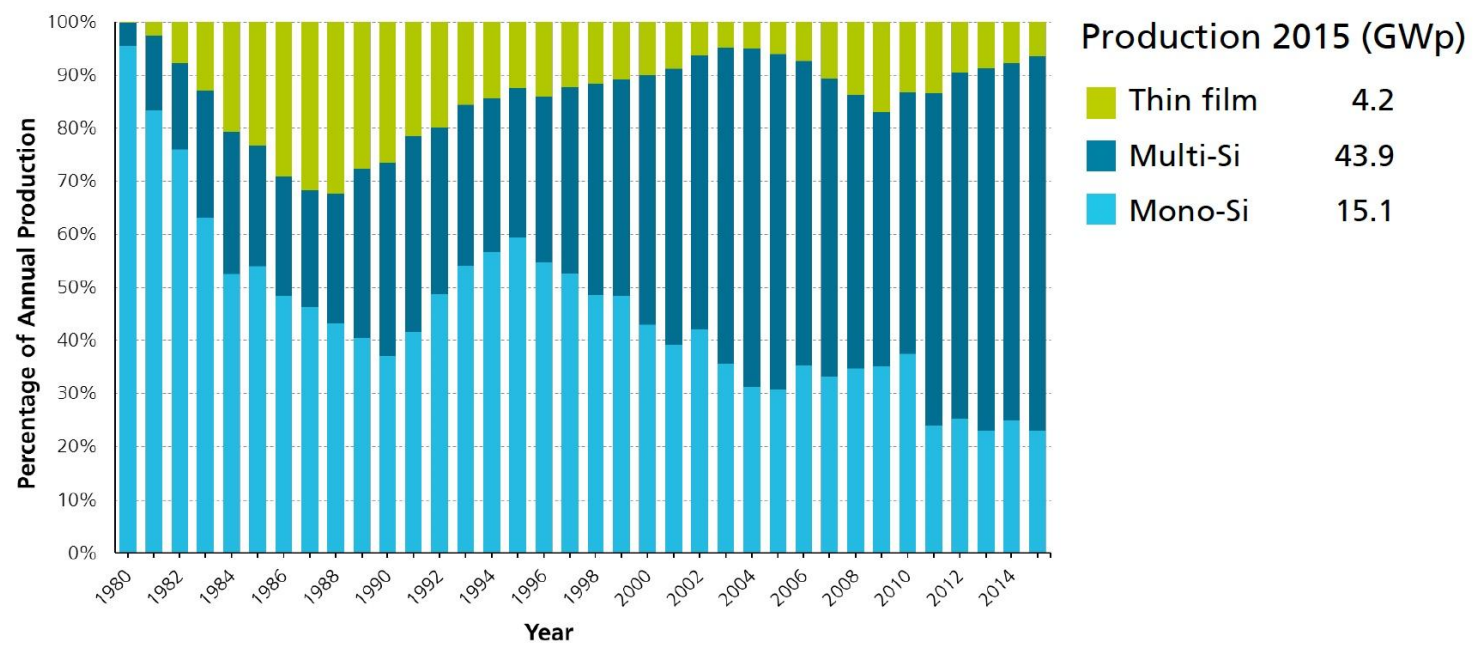

Data: from 2000 to 2010: Navigant; from 2011: IHS (Mono-/Multi- proportion from cell production). Graph: PSE AG 2016

Fig. 6: Global market share of PV technologies 1980 - 2015²

The dominant crystalline Si technology is approaching a ceiling of $29 \%$ efficiency, the Schottky-Queisser limit for a single-bandgap semiconductor. ${ }^{5} \mathrm{New}$ approaches for higher efficiencies require heterojunctions, and for those several approaches are possible. In the last years, multijunction heterojunctions were developed that offer the promise of efficiencies approaching 50\%, and the current world record of $46 \%$ under about 500x concentration has been achieved with this technology. ${ }^{4}$ However, these structures are very costly to produce, in order to be financially competitive a wafer is cut in 100s of small cells, and each cell is placed under a collecting lens, so that all light shining on the large area of that lens can be converted into electricity with the small, highest-efficiency cell. Because of the complex cell production technology and the need for two-axis tracking, this technology has not yet reached the GW-scale, that would allow truely cost-effective production.

A different technology approach does have the potential to take up an interesting share of the world PV market, and these are heterojunctions on silicon. Combining a suitable thin-film semiconductor with a good crystalline Si solar cell opens up the possibility to achieve efficiencies above $30 \%$, based on standard Si-based solar modules. The problem is, however, that depositing any other material on top of a good Si solar cells first degrades that cell's performance, and convincing examples of low-cost heterojunction technologies on Si solar cells still have to be demonstrated. The leading candidates surely are low-cost III-V deposition, or the deposition of Perovskite-based structures, a technology, that within the last five years showed the most impressive increase of cell efficiencies, exceeding already $22 \%$ today. ${ }^{6}$

In conclusion, we will experience the further development of photovoltaic technology into the Terawatt scale within the coming 10 years, by 2030 the world PV installations might be between 3 and $10 \mathrm{TW}$, and by 2050 might reach $50 \mathrm{TW}$ or more, at costs of PV-generated electricity around $1 \mathrm{ct} / \mathrm{kWh}$ or lower, clearly lower than all competing technologies to provide electricity. At such levels new technologies, such as electricity generation by nuclear fusion, have hardly any 
chance to compete. The coming years will see sustained global growth of the PV market, a doubling of the global PV production capacity can be expected within the next 5 years. It remains to be seen which countries will recognize this development early enough, to be able to secure an interesting share of the Terawatt-size global market of photovoltaic technology.

\section{REFERENCES}

[1] A. Palzer and H.M. Henning, "A Future German Energy System with a Dominating Contribution from Renewable Energies: A Holistic Model Based on Hourly Simulation," Energy Technology 2, 13 (2014).

[2] S. Philipps and W. Warmuth, Photovoltaics Report, Fraunhofer ISE 2017, https://www.ise.fraunhofer.de/content/dam/ise/de/documents/publications/studies/Photovoltaics-Report.pdf.

[3] N. M. Haegel, R. Margolis, T. Buonassisi, D. Feldman, A. Froitzheim, R. Garabedian, M. Green, S. Glunz, H.M. Henning, B. Holder, I. Kaizuka, B. Kroposki, K. Matsubara, S. Niki, K. Sakurai, R.A. Schindler, W. Tumas, E.R. Weber, G. Wilson, M. Woodhouse and S. Kurtz, "Terawatt-scale Photovoltaics: Trajectories and Challenges," Science 356, 141 (2017).

[4] E.R. Weber, S. Glunz, H.-M. Henning, A. Palzer, and R. Schindler, "Low-cost Harvesting of Solar Energy: the Future of Global Photovoltaics," in: Green Photonics and Electronics, Eds. G. Eisenstein and D. Bimberg, Springer 2017.

[5] W. Shockley and H.J. Queisser, "Detailed Balance Limit of Efficiency of p-n Junction Solar Cells", J. Appl. Phys. 32, 510 (1961).

[6] W. S. Yang, B.W. Park, E.H. Jung, N. J. Jeon, Y. C. Kim, D. U. Lee, S.S. Shi, J. Seo, E.K. Kim, J.H. Noh, S.I. Seok, "Iodide Management in Formamidinium-Lead-Halide-Based Perovskite Layers for Efficient Solar Cells," Science, 356, 6345 (2017).

\section{Author contact:}

Eicke R. Weber, BEARS, CREATE Tower, 1 Create Way \#11-02, Singapore 138602

Tel.: +65-6601-3193,E-Mail: weber@berkeley.edu 